\title{
A New Class of Contraction in $b$-Metric Spaces and Applications
}

\author{
Preeti Kaushik, ${ }^{1}$ Sanjay Kumar, ${ }^{1}$ and Kenan Tas ${ }^{2}$ \\ ${ }^{1}$ Department of Mathematics, DCRUST, Murthal, Sonepat 131 039, India \\ ${ }^{2}$ Department of Mathematics and Computer Science, Çankaya University, Ankara, Turkey
}

Correspondence should be addressed to Preeti Kaushik; preeti1785@gmail.com

Received 7 March 2017; Revised 27 April 2017; Accepted 8 May 2017; Published 11 June 2017

Academic Editor: Kunquan Lan

Copyright (C) 2017 Preeti Kaushik et al. This is an open access article distributed under the Creative Commons Attribution License, which permits unrestricted use, distribution, and reproduction in any medium, provided the original work is properly cited.

\begin{abstract}
A novel class of $\alpha$ - $\beta$-contraction for a pair of mappings is introduced in the setting of $b$-metric spaces. Existence and uniqueness of coincidence and common fixed points for such kind of mappings are investigated. Results are supported with relevant examples. At the end, results are applied to find the solution of an integral equation.
\end{abstract}

\section{Introduction and Prelims}

Fixed point theorems in metric spaces and generalized metric spaces provide a tool to solve many problems and have applications in nonlinear analysis and in many other fields. Most of the problems of applied mathematics reduce to solve a given equality which in turn may be reduced to find the fixed points of a certain mapping or the common fixed points of pairs of mappings. In order to solve particular problems, researchers tried to generalize various contraction conditions, auxiliary mappings, and metric spaces. Here, in this paper, we will present common fixed point theorems for $\alpha$ - $\beta$-contractive mappings in the framework of $b$-metric space. Therefore, to have a clear understanding of the paper, we will discuss the $b$-metric space, Geraghty type mappings, and $\alpha$-admissible mappings step by step.

The $b$-metric space or metric type space was introduced by Czerwik [1] in 1993. In this interesting paper, Czerwik [1] generalized the Banach contraction principle in the context of complete $b$-metric spaces. After that many researchers reported the existence and uniqueness of fixed points of various operators in the setting of $b$-metric spaces (see, e.g., [2-13] and some references therein).

Let us have a look on definitions, examples, and properties of $b$-metric space.

Definition 1 (see $[1,4])$. Let $X$ be a nonempty space, and let $s \geq 1$ be a given real number. A functional $d: X \times X \rightarrow[0, \infty)$ is said to be $b$-metric if the following conditions hold good:
(1) $d(x, y)=0$ if and only if $x=y$.

(2) $d(x, y)=d(y, x)$.

(3) $d(x, z) \leq s[d(x, y)+d(y, z)]$, for all $x, y$, and $z \in X$.

If $d$ satisfies all the above $b$-metric axioms, then the pair $(X, d)$ is called a $b$-metric or metric type space.

The class of $b$-metric spaces is larger than that of metric spaces, since a $b$-metric is a metric when $s=1$. All the metric spaces are $b$-metric spaces but not vice versa. We can illustrate this with the help of the following example.

Example 2. Let $X=\left\{x_{1}, x_{2}, x_{3}, x_{4}\right\}$ and $d\left(x_{1}, x_{2}\right)=k \geq 2$, $d\left(x_{1}, x_{3}\right)=d\left(x_{1}, x_{4}\right)=d\left(x_{2}, x_{3}\right)=d\left(x_{2}, x_{4}\right)=d\left(x_{3}, x_{4}\right)=1$, $d\left(x_{i}, x_{j}\right)=d\left(x_{j}, x_{i}\right)$ for $i, j=1,2,3,4$ and $d\left(x_{i}, x_{i}\right)=0, i=$ $1,2,3,4$.

Then

$$
\begin{aligned}
& d\left(x_{i}, x_{j}\right) \leq \frac{k}{2}\left[d\left(x_{i}, x_{n}\right)+d\left(x_{n}, x_{j}\right)\right] \\
& \qquad \text { for } n, i, j=1,2,3,4,
\end{aligned}
$$

and if $k>2$, the ordinary triangle inequality does not hold.

Definition 3 (see [1]). Let $(X, d)$ be a $b$-metric space.

(a) A sequence $\left\{x_{n}\right\}$ in $X$ is called $b$-convergent if and only if there exists $x \in X$ such that $d\left(x_{n}, x\right) \rightarrow 0$ as $n \rightarrow \infty$.

(b) The sequence $\left\{x_{n}\right\}$ in $X$ is said to be $b$-Cauchy if and only if $d\left(x_{n}, x_{m}\right) \rightarrow 0$, as $n, m \rightarrow \infty$. 
The $b$-metric space $(X, d)$ is called $b$-complete if every $b$ Cauchy sequence in $X$ is $b$-convergent.

The following lemmas are useful to prove our results.

Lemma 4 (see [9]). Let $(X, d)$ be a b-metric space and let $\left\{x_{n}\right\}$ be a sequence in $X$ such that

$$
\lim _{n \rightarrow \infty} d\left(x_{n}, x_{n+1}\right)=0 .
$$

If $\left\{x_{n}\right\}$ is not a b-Cauchy sequence, then there exist $\varepsilon>0$ and two sequences $\{m(k)\}$ and $\{n(k)\}$ of positive integers such that the four sequences

$$
\begin{gathered}
d\left(x_{m(k)}, x_{n(k)}\right), \\
d\left(x_{m(k)}, x_{n(k)+1}\right), \\
d\left(x_{m(k)+1}, x_{n(k)}\right), \\
d\left(x_{m(k)+1}, x_{n(k)+1}\right)
\end{gathered}
$$

exist and the following hold:

$$
\begin{aligned}
\varepsilon & \leq \lim _{k \rightarrow \infty} \inf d\left(x_{m(k)}, x_{n(k)}\right) \\
& \leq \lim _{k \rightarrow \infty} \sup d\left(x_{m(k)}, x_{n(k)}\right) \leq \varepsilon s, \\
\frac{\varepsilon}{s} & \leq \lim _{k \rightarrow \infty} \inf d\left(x_{m(k)}, x_{n(k)+1}\right) \\
& \leq \lim _{k \rightarrow \infty} \sup d\left(x_{m(k)}, x_{n(k)+1}\right) \leq \varepsilon s^{2}, \\
\frac{\varepsilon}{s} & \leq \lim _{k \rightarrow \infty} \inf d\left(x_{m(k)+1}, x_{n(k)}\right) \\
& \leq \lim _{k \rightarrow \infty} \sup d\left(x_{m(k)+1}, x_{n(k)}\right) \leq \varepsilon s^{2}, \\
\frac{\varepsilon}{s^{2}} & \leq \lim _{k \rightarrow \infty} \inf d\left(x_{m(k)+1}, x_{n(k)+1}\right) \\
& \leq \lim _{k \rightarrow \infty} \sup d\left(x_{m(k)+1}, x_{n(k)+1}\right) \leq \varepsilon s^{3} .
\end{aligned}
$$

Lemma 5 (see [9]). Let $(X, d)$ be a b-metric space and let $\left\{x_{n}\right\}$ and $\left\{y_{n}\right\}$ be b-convergent to $x$ and $y$, respectively. Then one has

$$
\begin{aligned}
\frac{1}{s^{2}} d(x, y) & \leq \lim _{n \rightarrow \infty} \inf d\left(x_{n}, y_{n}\right) \leq \lim _{n \rightarrow \infty} \sup d\left(x_{n}, y_{n}\right) \\
& \leq s^{2} d(x, y) .
\end{aligned}
$$

In particular, if $x=y$, then one has $\lim _{n \rightarrow \infty} d\left(x_{n}, y_{n}\right)=0$. Moreover, for each $z \in X$, one has

$$
\begin{aligned}
\frac{1}{s} d(x, z) & \leq \lim _{n \rightarrow \infty} \inf d\left(x_{n}, z\right) \leq \lim _{n \rightarrow \infty} \sup d\left(x_{n}, z\right) \\
& \leq s d(x, z) .
\end{aligned}
$$

Next, we address briefly the concept of Geraghty type mappings.

In 1973, Geraghty [14] generalized the Banach contraction principle in the setting of complete metric spaces by considering an auxiliary function. This function is known as Geraghty type function or mapping. Later on, many authors $[11,15-17]$ characterized the result of Geraghty in the context of various metric spaces and proved many interesting results. The definition of this new class of mapping is as follows.

Definition 6. Let $B$ denote the class of real functions $\beta$ : $[0,+\infty) \rightarrow[0,1)$ satisfying the condition

$$
\beta\left(t_{n}\right) \longrightarrow 1 \text { implies } t_{n} \longrightarrow 0 \text {. }
$$

For instance, consider the function given by $\beta(t)=e^{-2 t}$ for $t>0$ and $\beta(0) \in[0,1)$; here $\beta \in B$.

In 1973, Geraghty generalized the Banach contraction principle in the following form.

Theorem 7 (see $[14])$. Let $(X, d)$ be a complete metric space, and let $F: X \rightarrow X$ be a self-map.

Suppose that there exists $\beta \in B$ such that

$$
d(F x, F y) \leq \beta(d(x, y)) d(x, y)
$$

holds for all $x, y \in X$. Then $F$ has a unique fixed point $z \in X$ and for each $x \in X$ the Picard sequence $\left\{F^{n} x\right\}$ converges to $z$ when $n \rightarrow \infty$.

In 2011, Dukic et al. [16] introduced the Geraghty type $\beta$ functions in $b$-metric space as follows.

Definition 8 (see [16]). Let $(X, d)$ be a $b$-metric space with given $s>1$. Consider the class $B_{s}$ of real functions $\beta$ : $[0,+\infty) \rightarrow[0,1 / s)$ satisfying the property

$$
\beta\left(t_{n}\right) \longrightarrow \frac{1}{s} \text { implies } t_{n} \longrightarrow 0 \text {. }
$$

An example of a function in $B_{s}$ is given by $\beta(t)=1 / s e^{-t}$ for $t>0$ and $\beta(0) \in[0,1 / s)$.

Lastly, we discuss the $\alpha$-admissible mappings, examples, and alpha-admissibility for a pair of mappings.

The concept of $\alpha$-admissible mappings was introduced by Samet et al. [18] in 2012. They established some fixed point theorems for such mappings in complete metric spaces and showed some examples and applications to ordinary differential equations. Since then, many researchers extended the idea and generalized fixed point results for single-valued and multivalued $\alpha$-admissible mappings in various abstract spaces (see, e.g., $[2,3,11,19,20]$ and more references in the literature). The following definitions and examples reveal the basics of $\alpha$-admissible mappings.

Definition 9 (see [18]). A self-mapping $F: X \rightarrow X$ defined on a nonempty set $X$ is $\alpha$-admissible if, for all $x, y \in X$, one has

$$
\alpha(x, y) \geq 1 \Longrightarrow \alpha(F x, F y) \geq 1,
$$

where $\alpha: X \times X \rightarrow[0, \infty)$ is a given function under consideration. 
Example 10. Let $X=[0, \infty)$ and assume that $F: X \rightarrow X$ and $\alpha: X \times X \rightarrow[0, \infty)$ by $F x=\sqrt{ } x$, for all $x \in X$, and

$$
\alpha(x, y)= \begin{cases}e^{x-y} ; & x \geq y \\ 0 ; & x<y .\end{cases}
$$

Then $F$ is $\alpha$-admissible map.

In 2014, a new notion of $h$ - $\alpha$-admissible mapping was introduced by Rosa and Vetro [20]. The definition of this notion is as follows.

Definition 11 (see [20]). Let $F, h: X \rightarrow X$ be two selfmappings defined on a nonempty set $X$. And consider the map $\alpha: X \times X \rightarrow[0, \infty)$. Then mapping $F$ is called $h-\alpha$ admissible if, for all $x, y \in X$,

$$
\alpha(h x, h y) \geq 1 \text {, implies } \alpha(F x, F y) \geq 1 .
$$

Example 12. Let $X=[0, \infty)$. We will define the mapping $\alpha$ : $X \times X \rightarrow[0, \infty)$ by

$$
\alpha(x, y)= \begin{cases}1 ; & x \geq y \\ 0 ; & x<y\end{cases}
$$

and consider the mappings $F, h: X \rightarrow X$ by $F(x)=e^{x}$ and $h(x)=x^{2}$ for all $x \in X$. Then, the mapping $F$ is $h-\alpha$ admissible mapping.

Allahyari et al. [2] defined the $\alpha$-regular space with respect to some self-mapping defined on space as given below.

Definition 13 (see [2]). Let $(X, d)$ be a $b$-metric space. Suppose that $h: X \rightarrow X$ and $\alpha: X \times X \rightarrow[0, \infty)$ are two operators. $X$ is $\alpha$-regular with respect to $h$ if, for every sequence $\left\{x_{n}\right\} \in X, \alpha\left(h x_{n}, h x_{n+1}\right) \geq 1$ for all $n \in \mathbb{N}$ and $h x_{n} \rightarrow h x \in h(X)$ as $n \rightarrow \infty$; then there exists a subsequence $\left\{h x_{n(k)}\right\}$ of $\left\{h x_{n}\right\}$ such that, for all $k \in \mathbb{N}, \alpha\left(h x_{n(k)}, h x\right) \geq 1$.

Definition 14 (see [11]). Let $X$ be a nonempty set. Then the map $\alpha: X \times X \rightarrow[0, \infty)$ is called transitive if for $u, v, w \in X$ one has

$$
\begin{aligned}
\alpha(u, v) & \geq 1, \\
\alpha(v, w) & \geq 1 \\
& \\
\alpha(u, w) & \geq 1 .
\end{aligned}
$$

In 2014, Sintunavarat [11] proved the fixed point theorem for generalized $\alpha$ - $\beta$-contraction mapping in metric space and established Ulam-Hyers stability and well-posedness via fixed point results. The purpose of this paper is to define $\alpha$ - $\beta$ contraction mapping for a pair of mappings and to prove coincidence point and common fixed point theorems in the context of $b$-metric space. We will provide suitable examples to support our results. At the end, we will discuss some applications in the context of integral equations.

\section{Coincidence and Common Fixed Point Theorems}

First of all, we will present some definitions and results which will make our results easy to understand.

Definition 15. Let $F$ and $g$ be two self-mappings defined on a nonempty set $X$. Then a point $x \in X$ is called coincidence point of $F$ and $g$ if $F x=g x$. Moreover, if $x=F x=g x$, then $x$ is called common fixed point of $F$ and $g$.

Definition 16. Two self-mappings $F$ and $g$ defined on a nonempty set $X$ are weakly compatible if the maps commute at each coincidence point; that is, if $F x=g x$, for some $x \in X$, then $F g x=g F x$.

In 2014, Sintunavarat [11] defined the generalized $\alpha$ - $\beta$ contraction mapping in metric spaces as follows.

Definition 17 (see [11]). Let $F$ be a self-mapping on a nonempty set $X$ and there exist two functions $\alpha: X \times X \rightarrow$ $[0, \infty)$ and $\beta \in B$. We say that $F$ is $\alpha$ - $\beta$-contraction mapping if the following condition holds:

$$
\left[\alpha(x, y)-1+\delta_{*}\right]^{d(F x, F y)} \leq \delta^{\beta(d(x, y)) d(x, y)},
$$

for all $x, y \in X$, where $1<\delta \leq \delta_{*}$.

Now, we will introduce our notions in the setting of $b$ metric space.

Definition 18. Let $F$ and $g$ be two self-mappings defined on $b$-metric space $(X, d)$ with given $s>1$ and there exist two functions $\alpha: X \times X \rightarrow[0, \infty)$ and $\beta \in B_{s}$. We say that $F$ is $\alpha$ $\beta(b)$-contraction with respect to $g$ if the following condition holds:

$$
[\alpha(g x, g y)-1+\delta]^{d(F x, F y)} \leq \delta^{\beta(d(g x, g y)) d(g x, g y)},
$$

for all $x, y \in X$, where $1<\delta$.

Next, we present the coincidence and common fixed point theorems for a new class of contraction in $b$-metric space.

Theorem 19. Let $(X, d)$ be a complete b-metric space and let $F, g: X \rightarrow X$ be two self-mappings such that $F(x) \subseteq g(x)$ and one of these two subsets of $X$ is complete. Suppose that $F$ is $\alpha-\beta(b)$-contraction with respect to $g$ mapping satisfying the following conditions:

(i) $F$ is $g$ - $\alpha$-admissible and $\alpha$ is transitive mapping.

(ii) There exists $x_{0} \in X$ such that $\alpha\left(g x_{0}, F x_{0}\right) \geq 1$.

(iii) $X$ is $\alpha$-regular with respect to $g$.

Then $F$ and $g$ have a coincidence point.

Moreover, if $F$ and $g$ are weakly compatible and hypothesis has one more additional assumption,

(A1) either $\alpha(u, v) \geq 1$ or $\alpha(v, u) \geq 1$ whenever $F u=g u$ and $F v=g v$,

then $F$ and $g$ have a unique common fixed point. 
Proof. Let $x_{0} \in X$ such that $\alpha\left(g x_{0}, F x_{0}\right) \geq 1$. In order to prove that $F$ and $g$ have a point of coincidence and using $F(x) \subseteq$ $g(x)$, define two sequences $\left\{x_{n}\right\}$ and $\left\{y_{n}\right\}$ in $X$ such that

$$
y_{n}=F x_{n}=g x_{n+1} \quad \forall n \in \mathbb{N} \text {. }
$$

Now, if $y_{n}=y_{n+1}$ for any $n \in \mathbb{N}$, then $g x_{n+1}=y_{n}=y_{n+1}=$ $F x_{n+1}$ and $F$ and $g$ have a point of coincidence.

Without loss of generality, one can suppose that $y_{n} \neq y_{n+1}$ for each $n \in \mathbb{N}$.

Hence, $F$ is $g$ - $\alpha$-admissible and $\alpha\left(g x_{0}, g x_{1}\right)=$ $\alpha\left(g x_{0}, F x_{0}\right) \geq 1$. Similarly, $\alpha\left(g x_{1}, g x_{2}\right)=\alpha\left(F x_{0}, F x_{1}\right) \geq 1$. By induction, we can easily deduce

$$
\alpha\left(g x_{n-1}, g x_{n}\right) \geq 1 \quad \forall n \in \mathbb{N}
$$

Step 1. We shall show that $\lim _{n \rightarrow \infty} d\left(y_{n+1}, y_{n}\right)=0$. Now, it follows from (19) and (21) for each $n \in \mathbb{N}$ that

$$
\begin{aligned}
\delta^{d\left(y_{n+1}, y_{n}\right)} & =\delta^{d\left(F x_{n+1}, F x_{n}\right)} \\
& \leq\left[\alpha\left(g x_{n+1}, g x_{n}\right)-1+\delta\right]^{d\left(F x_{n+1}, F x_{n}\right)} \\
& \leq \delta^{\beta\left(d\left(g x_{n+1}, g x_{n}\right)\right) d\left(g x_{n+1}, g x_{n}\right)} .
\end{aligned}
$$

This implies that

$$
\begin{aligned}
d\left(y_{n+1}, y_{n}\right) & \leq \beta\left(d\left(g x_{n+1}, g x_{n}\right)\right) d\left(g x_{n+1}, g x_{n}\right) \\
& \leq \frac{1}{s} d\left(y_{n}, y_{n-1}\right) \quad \forall n \in \mathbb{N} .
\end{aligned}
$$

Further, from (23), it follows that

$$
\lim _{n \rightarrow \infty} d\left(y_{n+1}, y_{n}\right)=0 \text {. }
$$

Step 2. Next, we show that $\left\{y_{n}\right\}$ is a Cauchy sequence in $b$ metric space $X$. On the contrary, assume that $\left\{y_{n}\right\}$ is not a Cauchy sequence. Then there exists $\varepsilon>0$ and subsequences of integers $n_{p}$ and $m_{p}$ with $n_{p}>m_{p} \geq 0$ such that

$$
\begin{gathered}
d\left(y_{m_{p}}, y_{n_{p}}\right)>\varepsilon, \\
d\left(y_{m_{p}}, y_{n_{p-1}}\right)<\varepsilon,
\end{gathered}
$$

$$
\forall p \in \mathbb{N}
$$

Since $n_{p}>m_{p}$ and $\alpha$ is transitive mapping, we can deduce easily, by using triangle inequality,

$$
\alpha\left(g x_{m_{p+1}}, g x_{n_{p}}\right) \geq 1 \quad \forall p \in \mathbb{N} .
$$

Now, using (19) and (26), we can consider

$$
\begin{aligned}
\delta^{d\left(y_{m_{p+1}}, y_{n_{p}}\right)} & =\delta^{d\left(F x_{m_{p+1}}, F x_{n_{p}}\right)} \\
& \leq\left[\alpha\left(g x_{m_{p+1}}, g x_{n_{p}}\right)-1+\delta\right]^{d\left(F x_{m_{p+1}}, F x_{n_{p}}\right)} \\
& \leq \delta^{\beta\left(d\left(g x_{m_{p+1}}, g x_{n_{p}}\right)\right) d\left(g x_{m_{p+1}}, g x_{n_{p}}\right)}
\end{aligned}
$$

This gives

$$
\begin{aligned}
& d\left(y_{m_{p+1}}, y_{n_{p}}\right) \\
& \leq \beta\left(d\left(g x_{m_{p+1}}, g x_{n_{p}}\right)\right) d\left(g x_{m_{p+1}}, g x_{n_{p}}\right) \\
& \quad \leq \beta\left(d\left(y_{m_{p}}, y_{n_{p-1}}\right)\right) d\left(y_{m_{p}}, y_{n_{p-1}}\right) \\
& \quad \leq \beta\left(d\left(y_{m_{p}}, y_{n_{p-1}}\right)\right) \varepsilon \\
& \frac{d\left(y_{m_{p+1}}, y_{n_{p}}\right)}{\varepsilon} \leq \beta\left(d\left(y_{m_{p}}, y_{n_{p-1}}\right)\right)<\frac{1}{s}
\end{aligned}
$$

with $n_{p}>m_{p}>p$ for all $p \in \mathbb{N}$.

Hence, by Lemma 4 and (29), we have

$$
\begin{aligned}
\frac{1}{s} & =\frac{1}{\varepsilon} \frac{\varepsilon}{s} \leq \lim _{p \rightarrow \infty} \inf \frac{1}{\varepsilon} d\left(y_{m_{p+1}}, y_{n_{p}}\right) \\
& \leq \lim _{p \rightarrow \infty} \sup \frac{1}{\varepsilon} d\left(y_{m_{p+1}}, y_{n_{p}}\right) \\
& \leq \lim _{p \rightarrow \infty} \inf \beta\left(d\left(y_{m_{p}}, y_{n_{p-1}}\right)\right) \\
& \leq \lim _{p \rightarrow \infty} \sup \beta\left(d\left(y_{m_{p}}, y_{n_{p-1}}\right)\right) \leq \frac{1}{s} ;
\end{aligned}
$$

that is,

$$
\lim _{p \rightarrow \infty} \beta\left(d\left(y_{m_{p}}, y_{n_{p-1}}\right)\right)=\frac{1}{s}
$$

Also, $\beta \in B_{s}$ implies that $\lim _{p \rightarrow \infty} d\left(y_{m_{p}}, y_{n_{p-1}}\right)=0$. However, this is not possible, as, using (4) of Lemma 4, we get that

$$
\begin{aligned}
\frac{\varepsilon}{s} & \leq \frac{1}{s} d\left(y_{m_{p}}, y_{n_{p}}\right) \leq d\left(y_{m_{p}}, y_{n_{p-1}}\right)+d\left(y_{n_{p-1}}, y_{n_{p}}\right) \\
& \longrightarrow 0
\end{aligned}
$$

as $p \rightarrow \infty$, which leads to contradicting (25).

Therefore, $\left\{y_{n}\right\}$ is a $b$-Cauchy sequence and by hypothesis we can suppose that $g(X)$ is to be complete subspace of $X$ (proof can be derived in a similar manner when $F(X)$ is supposed to be complete). Then $b$-completeness of $g(X)$ implies that $\left\{y_{n}\right\}=\left\{F x_{n}\right\}=\left\{g x_{n+1}\right\} b$-converges to a point $u \in g(X)$, where $u=g z$ for some $z \in X$, or in other words

$$
\lim _{n \rightarrow \infty} F x_{n}=\lim _{n \rightarrow \infty} g x_{n}=g z \quad \text { for some } z \in X
$$

Step 3. Next, we will prove that $F z=g z$. Since $X$ is $\alpha$-regular with respect to $g$ and using (33), we have

$$
\alpha\left(g x_{n(p)}, g z\right) \geq 1 \quad \forall p \in \mathbb{N}
$$


To show $F z=g z$, we consider

$$
\begin{aligned}
\delta^{d(F z, g z)} \leq & \delta^{s d\left(F z, F x_{n(p)}\right)+s d\left(g x_{n(p)+1}, g z\right)} \\
\leq & \delta^{s d\left(F z, F x_{n(p)}\right)} \times \delta^{s d\left(g x_{n(p)+1}, g z\right)} \\
\leq & {\left[\alpha\left(g z, g x_{n(p)}\right)-1+\delta\right]^{s d\left(F z, F x_{n(p)}\right)} } \\
& \times \delta^{s d\left(g x_{n(p)+1}, g z\right)} \\
\leq & \delta^{s \beta\left(d\left(g z, g x_{n(p)}\right)\right) d\left(g z, g x_{n(p)}\right)} \times \delta^{s d\left(g x_{n(p)+1}, g z\right)} .
\end{aligned}
$$

This in turns implies that

$$
\begin{aligned}
d(F z, g z) \leq & s \beta\left(d\left(g z, g x_{n(p)}\right)\right) d\left(g z, g x_{n(p)}\right) \\
& +s d\left(g x_{n(p)+1}, g z\right) \\
\frac{1}{s} d(F z, g z) \leq & \beta\left(d\left(g z, g x_{n(p)}\right)\right) d\left(g z, g x_{n(p)}\right) \\
& +d\left(g x_{n(p)+1}, g z\right) \\
< & \frac{1}{s} d\left(g z, g x_{n(p)}\right)+d\left(g x_{n(p)+1}, g z\right) \\
\longrightarrow & 0 \text { as } n \longrightarrow \infty .
\end{aligned}
$$

Thus, $F z=g z=u$ is a point of coincidence of $F$ and $g$.

Step 4. Next, we prove that $F$ and $g$ have a common fixed point. Firstly, we claim that if $F u=g u$ and $F v=g v$, then $g u=g v$. By hypotheses, $\alpha(u, v) \geq 1$ or $\alpha(v, u) \geq 1$. Suppose that $\alpha(u, v) \geq 1$ and consider that

$$
\begin{aligned}
\delta^{d(g u, g v)} & =\delta^{d(F u, F v)} \leq[\alpha(g u, g v)-1+\delta]^{d(F u, F v)} \\
& \leq \delta^{\beta(d(g u, g v)) d(g u, g v)} .
\end{aligned}
$$

Then we get that

$$
\begin{aligned}
& d(g u, g v) \leq \beta(d(g u, g v)) d(g u, g v) \\
& d(g u, g v) \leq d(g u, g v),
\end{aligned}
$$

which is a contradiction.

Therefore, we conclude that $g u=g v$. If we take $\alpha(v, u) \geq$ 1 , then we also get the same result.

Secondly, If $F$ and $g$ are weakly compatible, then, for any $u \in X$, if $u=F v=g v$ (because $F$ and $g$ have a point of coincidence, proven earlier in Step 3), then, using weak compatibility of $F$ and $g$, we get

$$
F u=F(g v)=g(F v)=g u .
$$

Thus $u$ is a coincidence point of $F$ and $g$; then, using the result in first part, $g u=g v$, which leads to $F u=g u=g v=$ $F v=u$.

Therefore, $u$ is a common fixed point of $F$ and $g$.

We can prove the uniqueness of the common fixed point of $F$ and $g$ by making use of condition (19) and assumption (A1) of hypothesis. The proof is very simple; therefore we do not go through details.
If we consider $g$ as identity mapping in the above theorem, we deduce the following corollary.

Corollary 20. Let $(X, d)$ be a complete b-metric space and let $F: X \rightarrow X$ be continuous $\alpha$-admissible mapping satisfying the following condition:

$$
[\alpha(x, y)-1+\delta]^{d(F x, F y)} \leq \delta^{\beta(d(x, y)) d(x, y)},
$$

for all $x, y \in X$ and $\beta \in B_{s}$, where $1<\delta$.

If $\alpha$ is transitive mapping and there exists $x_{0} \in X$ such that $\alpha\left(x_{0}, F x_{0}\right) \geq 1$, then $F$ has a fixed point.

Taking $\alpha(x, y)=1$ and $\delta=1$ in Corollary 20, we get the following variant of Geraghty theorem.

Corollary 21. Let $(X, d)$ be a complete b-metric space and let $F: X \rightarrow X$ be self-mapping satisfying the following condition:

$$
d(F x, F y) \leq \beta(d(x, y)) d(x, y),
$$

for all $x, y \in X$ and $\beta \in B_{s}$. Then $F$ has a unique fixed point $z \in X$ and, for each $x \in X$, the Picard sequence $\left\{F^{n} x\right\}$ converges to $z$ when $n \rightarrow \infty$.

The following lemma derived from [7] is very useful to prove our next theorem.

Lemma 22 (see [7]). Let $\left\{y_{n}\right\}$ be a sequence in a metric type space or b-metric space $(X, d)$ such that

$$
d\left(y_{n+1}, y_{n}\right) \leq \lambda d\left(y_{n}, y_{n-1}\right)
$$

for some $\lambda, 0<\lambda<1 /$ s and each $n=1,2, \ldots$. Then $\left\{y_{n}\right\}$ is a Cauchy sequence in $X$.

Theorem 23. Let $(X, d)$ be a complete b-metric space and be $\alpha$-regular with respect to $g$. And let $F, g: X \rightarrow X$ be two selfmappings, where $F$ is $g$ - $\alpha$-admissible and $\alpha$ is transitive, and, for $x_{0} \in X$, one has $\alpha\left(g x_{0}, F x_{0}\right) \geq 1$. If $F(x) \subseteq g(x)$ and one of these two subsets of $X$ is complete, suppose that there exists $\lambda \in[0,1 / s)$ such that

$$
[\alpha(g x, g y)-1+\delta]^{d(F x, F y)} \leq \delta^{\lambda M(F, g ; x, y)}
$$

for all $x, y \in X$ and $1<\delta$.

Consider

$$
\begin{gathered}
M(F, g ; x, y)=\max \{d(g x, g y), d(g x, F x), \\
\left.d(g y, F y), \frac{d(g x, F y)+d(g y, F x)}{2 s}\right\} .
\end{gathered}
$$

Then $F$ and $g$ have a coincidence point.

Moreover, if $F$ and $g$ are weakly compatible and hypothesis has one more additional assumption,

(A1) either $\alpha(u, v) \geq 1$ or $\alpha(v, u) \geq 1$ whenever $F u=g u$ and $F v=g v$,

then $F$ and $g$ have a unique common fixed point. 
Proof. Let $x_{0} \in X$ be arbitrary and, using condition $F(X) \subseteq g(X)$, we can easily construct a Jungck sequence $\left\{y_{n}\right\}$ satisfying

$$
y_{n}=F x_{n}=g x_{n+1} \quad \forall n \in \mathbb{N} .
$$

Now, if $y_{n}=y_{n+1}$ for any $n \in \mathbb{N}$, then $g x_{n+1}=y_{n}=y_{n+1}=$ $F x_{n+1}$ and $F$ and $g$ have a point of coincidence.

Without loss of generality, we assume that $y_{n} \neq y_{n+1}$ for each $n \in \mathbb{N}$.

Hence, $F$ is $g$ - $\alpha$-admissible and $\alpha\left(g x_{0}, g x_{1}\right)=\alpha\left(g x_{0}\right.$, $\left.F x_{0}\right) \geq 1$. Similarly, $\alpha\left(g x_{1}, g x_{2}\right)=\alpha\left(F x_{0}, F x_{1}\right) \geq 1$. By induction, we can easily deduce

$$
\alpha\left(g x_{n-1}, g x_{n}\right) \geq 1 \quad \forall n \in \mathbb{N} .
$$

Step 1 . We shall show that $\left\{y_{n}\right\}$ is a $b$-Cauchy sequence. Now, taking (43) and (46), we obtain, for each $n \in \mathbb{N}$,

$$
\begin{aligned}
\delta^{d\left(y_{n+1}, y_{n}\right)} & =\delta^{d\left(F x_{n+1}, F x_{n}\right)} \\
& \leq\left[\alpha\left(g x_{n+1}, g x_{n}\right)-1+\delta\right]^{d\left(F x_{n+1}, F x_{n}\right)} \\
& \leq \delta^{\lambda M\left(F, g ; x_{n+1}, x_{n}\right)} .
\end{aligned}
$$

This implies that

$$
d\left(y_{n+1}, y_{n}\right) \leq \lambda M\left(F, g ; x_{n+1}, x_{n}\right)
$$

or

$$
\begin{aligned}
& d\left(y_{n+1}, y_{n}\right) \leq \lambda \max \left\{d\left(g x_{n+1}, g x_{n}\right),\right. \\
& d\left(g x_{n+1}, F x_{n+1}\right), d\left(g x_{n}, F x_{n}\right), \\
& \left.\frac{d\left(g x_{n+1}, F x_{n}\right)+d\left(g x_{n}, F x_{n+1}\right)}{2 s}\right\} \\
& \leq \lambda \max \left\{d\left(y_{n}, y_{n-1}\right), d\left(y_{n}, y_{n+1}\right), d\left(y_{n-1}, y_{n}\right),\right. \\
& \left.\quad \frac{d\left(y_{n}, y_{n}\right)+d\left(y_{n-1}, y_{n+1}\right)}{2 s}\right\} \\
& \leq \lambda \max \left\{d\left(y_{n}, y_{n-1}\right), \frac{d\left(y_{n-1}, y_{n}\right)+d\left(y_{n}, y_{n+1}\right)}{2}\right\} .
\end{aligned}
$$

Now, if $\max \left\{d\left(y_{n}, y_{n-1}\right),\left(d\left(y_{n-1}, y_{n}\right)+d\left(y_{n}, y_{n+1}\right)\right) / 2\right\}=$ $\left(d\left(y_{n-1}, y_{n}\right)+d\left(y_{n}, y_{n+1}\right)\right) / 2$, then $d\left(y_{n}, y_{n-1}\right)<\left(d\left(y_{n-1}, y_{n}\right)+\right.$ $\left.d\left(y_{n}, y_{n+1}\right)\right) / 2<d\left(y_{n+1}, y_{n}\right)$.

Then (49) implies that

$$
d\left(y_{n+1}, y_{n}\right) \leq \lambda d\left(y_{n+1}, y_{n}\right),
$$

which is impossible as $\lambda<1$.

Therefore, we deduce that $\max \left\{d\left(y_{n}, y_{n-1}\right),\left(d\left(y_{n-1}, y_{n}\right)+\right.\right.$ $\left.\left.d\left(y_{n}, y_{n+1}\right)\right) / 2\right\}=d\left(y_{n}, y_{n-1}\right)$.

This in turn implies that

$$
d\left(y_{n+1}, y_{n}\right) \leq \lambda d\left(y_{n}, y_{n-1}\right)
$$

Using Lemma 22, we obtain that $\left\{y_{n}\right\}$ is a $b$-Cauchy sequence and by hypothesis we can suppose that $g(X)$ is to be complete subspace of $X$ (the proof when $F(X)$ is similar). Then $b$-completeness of $g(X)$ implies that $\left\{y_{n}\right\}=\left\{F x_{n}\right\}=$ $\left\{g x_{n+1}\right\} b$-converges to a point $u \in g(X)$, where $u=g z$ for some $z \in X$, or in other words

$$
\lim _{n \rightarrow \infty} F x_{n}=\lim _{n \rightarrow \infty} g x_{n}=g z \quad \text { for some } z \in X
$$

Step 2. Next, we will prove that $F z=g z$. Since $X$ is $\alpha$-regular with respect to $g$ and using (52), we have

$$
\alpha\left(g x_{n(p)}, g z\right) \geq 1 \quad \forall p \in \mathbb{N}
$$

To show $F z=g z$, we consider

$$
\begin{aligned}
& \delta^{d\left(F x_{n(p)}, F z\right)} \\
& \leq\left[\alpha\left(g x_{n(p)}, g z\right)-1+\delta\right]^{d\left(F x_{n(p)}, F z\right)} \leq \delta^{\lambda M\left(F, g ; x_{n(p)}, z\right)} .
\end{aligned}
$$

This implies that

$$
d\left(F x_{n(p)}, F z\right) \leq \lambda M\left(F, g ; x_{n(p)}, z\right)
$$

or

$$
\begin{gathered}
d\left(F x_{n(p)}, F z\right) \leq \lambda \max \left\{d\left(g x_{n(p)}, g z\right),\right. \\
d\left(g x_{n(p)}, F x_{n(p)}\right), d(g z, F z), \\
\left.\frac{d\left(g x_{n(p)}, F z\right)+d\left(g z, F x_{n(p)}\right)}{2 s}\right\} .
\end{gathered}
$$
that

Also, $F x_{n(p)} \rightarrow g z$ and $g x_{n(p)} \rightarrow g z$ as $n \rightarrow \infty$, implying

$$
\begin{aligned}
d\left(g x_{n(p)}, F x_{n(p)}\right) & =s d\left(g x_{n(p)}, g z\right)+s d\left(g z, F x_{n(p)}\right) \\
& \longrightarrow 0 \quad \text { as } n \longrightarrow \infty
\end{aligned}
$$

Then we have only two cases.

Case 1

$$
\begin{aligned}
& d\left(F x_{n(p)}, F z\right) \leq \lambda d(g z, F z) \\
& \quad \leq \lambda s\left(d\left(g z, F x_{n(p)}\right)+d\left(F x_{n(p)}, F z\right)\right) \\
& (1-\lambda s) d\left(F x_{n(p)}, F z\right) \leq \lambda s d\left(g z, F x_{n(p)}\right) \longrightarrow 0
\end{aligned}
$$


Since $1-\lambda s>0$, it follows that $F x_{n(p)} \rightarrow F z$.

Case 2

$$
\begin{aligned}
d\left(F x_{n(p)}, F z\right) \leq \lambda \frac{d\left(g x_{n(p)}, F z\right)}{2 s} & \\
\leq \lambda s\left(\frac{d\left(g x_{n(p)}, F x_{n(p)}\right)+d\left(F x_{n(p)}, F z\right)}{2 s}\right) & \\
\left(1-\frac{\lambda}{2}\right) d\left(F x_{n(p)}, F z\right) \leq \frac{\lambda}{2} d\left(g x_{n(p)}, F x_{n(p)}\right) & \longrightarrow 0 \\
\text { as } n & \longrightarrow \infty .
\end{aligned}
$$

Since $1-\lambda / 2>0$, it follows that $F x_{n(p)} \rightarrow F z$.

Uniqueness of the limit of a sequence implies that $F z=$ gz.

Using conditions (A1) and weak compatibility of $F$ and $g$ of hypothesis, we can easily prove that $F$ and $g$ have a unique common fixed point.

From the above theorem, one can deduce the following corollary easily.

Corollary 24. Let $(X, d)$ be a complete b-metric space and $F$ : $X \rightarrow X$ is continuous and $\alpha$-admissible. Suppose that there exists $\lambda \in[0,1 / s)$ such that

$$
[\alpha(x, y)-1+\delta]^{d(F x, F y)} \leq \delta^{\lambda M(x, y)}
$$

for all $x, y \in X$ and $1<\delta$.

Consider

$$
\begin{aligned}
& M(x, y)=\max \{d(x, y), d(x, F x), d(y, F y), \\
& \left.\frac{d(x, F y)+d(y, F x)}{2 s}\right\} .
\end{aligned}
$$

If $\alpha$ is a transitive mapping and there exists $x_{0} \in X$ such that $\alpha\left(x_{0}, F x_{0}\right) \geq 1$, then $F$ has a fixed point.

Taking $\alpha(x, y)=1$ and $\delta=1$, we get the following variant of Corollary 3.12 of [7].

Corollary 25. Let $(X, d)$ be a complete b-metric space and let $F: X \rightarrow X$ be self-mapping. Suppose that there exists $\lambda \in$ $[0,1 / s)$ such that, for all $x, y \in X$,

$$
d(F x, F y) \leq \lambda M(x, y),
$$

where

$$
\begin{aligned}
& M(x, y)=\max \{d(x, y), d(x, F x), d(y, F y), \\
& \left.\frac{d(x, F y)+d(y, F x)}{2 s}\right\} .
\end{aligned}
$$

Then $F$ has a unique fixed point $z \in X$.
In what follows, we furnish illustrative examples wherein one demonstrates Theorems 19 and 23 on the existence and uniqueness of a common fixed point.

Example 26. Let $X=\{0,1,3\}$ be a $b$-metric space with metric $d$ given by $d(x, y)=(x-y)^{2}$ with $s=2$. Consider the mappings $F, g: X \rightarrow X$ defined by $F(0)=1, F(1)=1$, and $F(3)=1$, and $g$ by $g(0)=1, g(1)=1$, and $g(3)=3$. Let us take $\beta \in B_{s}$, as $\beta(t)=1 / 2$ for $t>0$ and $\beta(0) \in[0,1 / 2)$.

And $\alpha: X \times X \rightarrow[0, \infty)$ by

$$
\alpha(x, y)= \begin{cases}1, & \text { when } x, y \geq 0 \\ 0, & \text { otherwise }\end{cases}
$$

then one can examine easily that

$$
\begin{aligned}
d(F 0, F 1) & =d(1,1)=0, \\
\beta(d(g 0, g 1)) d(g 0, g 1) & =\beta(d(1,1)) d(1,1)=0 \\
d(F 0, F 3) & =d(1,1)=0, \\
\beta(d(g 0, g 3)) d(g 0, g 3) & =\beta(d(1,3)) d(1,3)=2 \\
d(F 1, F 3) & =d(1,1)=0, \\
\beta(d(g 1, g 3)) d(g 1, g 3) & =\beta(d(1,3)) d(1,3)=2 .
\end{aligned}
$$

Thus, in all cases, we get

$$
[\alpha(g x, g y)-1+\delta]^{d(F x, F y)} \leq \delta^{\beta(d(g x, g y)) d(g x, g y)}
$$

for all $x, y \in X$, where $1<\delta$.

Also we can check that $F$ and $g$ satisfy all the other assumptions of Theorem 19 and thus the pair $F$ and $g$ has a unique common fixed point $x=1$.

Example 27. Let $X=\{0,1,3\}$ be a $b$-metric space with metric $d$ given by $d(x, y)=(x-y)^{2}$ with $s=2$. Consider the mappings $F, g: X \rightarrow X$ defined by $F(0)=0, F(1)=1$, and $F(3)=0$ and $g$ by $g(0)=3, g(1)=1$, and $g(3)=0$. Let us take $\lambda \in[0,1 / 2)$.

And $\alpha: X \times X \rightarrow[0, \infty)$ by

$$
\alpha(x, y)= \begin{cases}1, & \text { when } x, y \geq 0 \\ 0, & \text { otherwise }\end{cases}
$$

Now, we verify Theorem 23 by considering the following cases. 
Case 1 (take points 0 and 1 ).

$$
\begin{aligned}
& d(F 0, F 1)=d(0,1)=1 \\
& d(g 0, g 1)=d(3,1)=4 \\
& d(g 0, F 0)=d(3,0)=9 \\
& d(g 1, F 1)=d(1,1)=0 \\
& \frac{d(g 0, F 1)+d(g 1, F 0)}{2 \cdot 2}=\frac{d(3,1)+d(1,0)}{4}=\frac{4+1}{4} \\
& \quad=\frac{5}{4} . \\
& M(F, g ; 0,1)=\max \{d(g 0, g 1), d(g 0, F 0), \\
& \left.\quad d(g 1, F 1), \frac{d(g 0, F 1)+d(g 1, F 0)}{4}\right\}=\left\{4,9,0, \frac{5}{4}\right\} \\
& \quad=9
\end{aligned}
$$

Case 2 (take points 1 and 3).

$$
\begin{aligned}
& d(F 1, F 3)=d(1,1)=0, \\
& M(F, g ; 1,3)=\max \{d(g 1, g 3), d(g 1, F 1), \\
& \left.\quad d(g 3, F 3), \frac{d(g 1, F 3)+d(g 3, F 1)}{4}\right\}=\left\{1,0,0, \frac{2}{4}\right\} \\
& \quad=1 .
\end{aligned}
$$

Case 3 (take points 0 and 3).

$$
\begin{aligned}
& d(F 0, F 3)=d(0,0)=0, \\
& M(F, g ; 0,3)=\max \{d(g 0, g 3), d(g 0, F 0), \\
& \left.d(g 3, F 3), \frac{d(g 0, F 3)+d(g 3, F 0)}{4}\right\}=\left\{9,9,0, \frac{9}{4}\right\}
\end{aligned}
$$

$$
=9 \text {. }
$$

Thus, in all cases, $F$ and $g$ satisfy all the assumptions of Theorem 23 and thus the pair $F$ and $g$ has a unique common fixed point $x=1$.

\section{An Application to an Integral Equation}

This section deals with the applications of results proven in the previous section. Here, we will investigate the solution of integral equation through our results.

Consider the following integral equation:

$$
x(t)=\int_{0}^{1} K(t, r, x(r)) d r
$$

where $K:[0,1] \times[0,1] \times \mathbb{R} \rightarrow \mathbb{R}$.
Let $X=C[0,1]$ be the set of continuous real functions defined on $[0,1]$. Define the $b$-metric by $d(x(t), y(t))=$ $\max _{t \in[0,1]}(|x(t)|+|y(t)|)^{p}$ for all $x, y \in X$.

Consider $p>1$. Then $(X, d)$ is a complete $b$-metric space with the constant $s=2^{p-1}$.

$F(x(t))=\int_{0}^{1} K(t, r, x(r)) d r$ for all $x \in X$ and for all $t \epsilon$ $[0,1]$. Then the existence of a solution to (71) is equivalent to the existence of a fixed point of $F$. Now, we prove the following result.

Theorem 28. Let us suppose that the following hypotheses hold:

(i) $K:[0,1] \times[0,1] \times \mathbb{R} \rightarrow \mathbb{R}$ is continuous.

(ii) For all $t, r \in[0,1]$, there exists a continuous operator $\xi:[0,1] \times[0,1] \rightarrow \mathbb{R}$ such that

$$
\begin{aligned}
& |K(t, r, x(r))|+|K(t, r, y(r))| \\
& \quad<\lambda^{1 / p} \xi(t, r)(|x(r)|+|y(r)|), \\
& \sup _{t \in[0,1]} \int_{0}^{1} \xi(t, r) d r \leq 1,
\end{aligned}
$$

where $0<\lambda<1 / s$.

(iii) There exists a function $\mu: \mathbb{R}^{2} \rightarrow \mathbb{R}$ such that, for all $t \in I$ and for all $a, b \in \mathbb{R}$ with $\mu(a, b) \geq 0$, we have

$$
\begin{array}{r}
\mu\left(x_{1}(t), \int_{0}^{1} K(t, r, x(r)) d r\right) \geq 0 \\
\text { for } x \in C(I), \forall t \in I, \\
\mu(x(t), y(t)) \geq 0, \\
\mu\left(\int_{0}^{1} K(t, r, x(r)), \int_{0}^{1} K(t, r, y(r)) d r\right) \geq 0, \\
\forall t \in I, \forall x, y \in C(I) .
\end{array}
$$
$X$.

Then the integral equation (71) has a unique solution $x \in$

Proof. We define $\alpha: C(I) \times C(I) \rightarrow[0, \infty)$ by

$$
\alpha(x, y)= \begin{cases}1, & \text { when } \mu(x(t), y(t)) \geq 0 \\ 0, & \text { otherwise. }\end{cases}
$$

Then, for all $x, y \in C(I)$, we have $\alpha(x, y)=1$ and $\alpha(y, z)=1$, implying that $\alpha(x, z)=1$ for all $x, y, z \in C(I)$, which proves that $\alpha$ is a transitive mapping.

If $\alpha(x, y)=1$ for all $x, y \in C(I)$, then $\mu(x(t), y(t)) \geq 0$. From (iii), we have $\mu(F x(t), F y(t)) \geq 0$, and so $\alpha(F x, F y)=1$. Thus, $F$ is $\alpha$-admissible.

From (iii), there exists $x_{1} \in C(I)$ such that $\alpha\left(x_{1}, F x_{1}\right)=1$. 
Also we observe from (72) that

$$
\begin{aligned}
(\mid F x & (t)|+| F y(t) \mid)^{p} \\
& =\left(\left|\int_{0}^{1} K(t, r, x(r)) d r\right|+\left|\int_{0}^{1} K(t, r, y(r)) d r\right|\right)^{p} \\
& \leq\left(\int_{0}^{1}|K(t, r, x(r))| d r+\int_{0}^{1}|K(t, r, y(r))| d r\right)^{p} \\
& \leq\left(\int_{0}^{1}(|K(t, r, x(r))|+|K(t, r, y(r))|) d r\right)^{p} \\
& \leq\left(\int_{0}^{1}\left(\lambda^{1 / p} \xi(t, r)(|x(r)|+|y(r)|)\right) d r\right)^{p} \\
& =\left(\int_{0}^{1}\left(\lambda^{1 / p} \xi(t, r)\left((|x(r)|+|y(r)|)^{p}\right)^{1 / p}\right) d r\right)^{p} \\
& \leq\left(\int_{0}^{1} \lambda^{1 / p} \xi(t, r) d^{1 / p}(x(r), y(r)) d r\right)^{p} \\
& \leq \lambda d(x(t), y(t))\left(\int_{0}^{1} \xi(t, r) d r\right)^{p} \\
& =\lambda(t), y(t)) \leq \lambda M(x(t), y(t)),
\end{aligned}
$$

which in turn implies that $[\alpha(x, y)-1+\delta]^{d(F x, F y)} \leq \delta^{\lambda M(x, y)}$.

Now, all the conditions of Corollary 24 hold and $F$ has a unique fixed point $x \in X$, which means that $x$ is the unique solution for the integral equation (71).

\section{Conclusion}

To conclude, we can assert that our results are novel, interesting, and generalized while considering the alphaadmissible Geraghty type mappings. These results extend, improve, unify, and generalize many theorems based on alpha-admissible mappings in $b$-metric spaces. Examples are presented in a simplest form and illustrate the theorems. Application to integral equation adds value to our research.

\section{Conflicts of Interest}

All the authors of this article declare that they have no conflicts of interest regarding the publication of this article.

\section{Authors' Contributions}

All authors have equal contribution in writing this paper. All authors read and approved the final paper.

\section{References}

[1] S. Czerwik, "Contraction mappings in b-metric spaces," Acta Mathematica et Informatica Universitatis Ostraviensis, vol. 1, pp. 5-11, 1993.

[2] R. Allahyari, R. Arab, and A. S. Haghighi, "Fixed points of admissible almost contractive type mappings on $b$-metric spaces with an application to quadratic integral equations," Journal of Inequalities and Applications, vol. 2015, no. 32, 18 pages, 2015.

[3] M.-F. Bota, E. Karapinar, and O. Mlesnite, "Ulam-hyers stability results for fixed point problems via $\alpha$ - $\psi$-contractive mapping in (b)-metric space," Abstract and Applied Analysis, vol. 2013, Article ID 825293, 6 pages, 2013.

[4] I. A. Bakhtin, "The contraction mapping principle in almost metric space," Functional Analysis, vol. 30, pp. 26-37, 1989.

[5] C. Chen, J. Dong, and C. Zhu, "Some fixed point theorems in b-metric-like spaces," Fixed Point Theory and Applications, vol. 2015, no. 122, 10 pages, 2015.

[6] H.-S. Ding, M. Imdad, S. Radenovic, and J. Vujakovic, "On some fixed point results in $b$-metric, rectangular and $b$-rectangular metric spaces," Arab Journal of Mathematical Sciences, vol. 22, (2016), pp. 151-164, 2015.

[7] S. Radenović, M. Jovanović, and Z. Kadelburg, "Common fixed point results in metric-type spaces," Fixed Point Theory and Applications, vol. 2010, article 978121, 15 pages, 2010.

[8] M. A. Khamsi, "Remarks on cone metric spaces and fixed point theorems of contractive mappings," Fixed Point Theory and Applications, vol. 2010, article 315398, 2010.

[9] J. R. Roshan, V. Parvaneh, and Z. Kadelburg, “Common fixed point theorems for weakly isotone increasing mappings in ordered b-metric spaces," Journal of Nonlinear Science and its Applications. JNSA, vol. 7, no. 4, pp. 229-245, 2014.

[10] W. Sintunavarat, S. Plubtieng, and P. Katchang, "Fixed point result and applications on a $b$-metric space endowed with an arbitrary binary relation," Fixed Point Theory and Applications, vol. 2013, article 296, 2013.

[11] W. Sintunavarat, "Generalized Ulam-Hyers stability, wellposedness, and limit shadowing of fixed point problems for $\alpha$ $\beta$-contraction mapping in metric spaces," The Scientific World Journal, vol. 2014, Article ID 569174, 7 pages, 2014.

[12] R. J. Shahkoohi and A. Razani, "Some fixed point theorems for rational Geraghty contractive mappings in ordered $b$-metric spaces," Journal of Inequalities and Applications, vol. 373, p. 23, 2014.

[13] S. L. Singh and B. Prasad, "Some coincidence theorems and stability of iterative procedures," Computers \& Mathematics with Applications, vol. 55, no. 11, pp. 2512-2520, 2008.

[14] M. A. Geraghty, "On contractive mappings," Proceedings of the American Mathematical Society, vol. 40, pp. 604-608, 1973.

[15] S. Cho, J. Bae, and E. Karapınar, "Fixed point theorems for $\alpha$ Geraghty contraction type maps in metric spaces," Fixed Point Theory and Applications, vol. 2013, no. 329, 11 pages, 2013.

[16] D. Dukic, Z. Kadelburg, and S. Radenovic, "Fixed points of Geraghty-type mappings in various generalized metric spaces," Abstract and Applied Analysis, vol. 2011, Article ID 561245, 13 pages, 2011.

[17] M. E. Gordji, M. Ramezani, Y. J. Cho, and S. Pirbavafa, "A generalization of Geraghty's theorem in partially ordered metric spaces and applications to ordinary differential equations," Fixed Point Theory and Applications, vol. 2012, article 74, 2012.

[18] B. Samet, C. Vetro, and P. Vetro, "Fixed point theorems for $\alpha-\psi$-contractive type mappings," Nonlinear Analysis: Theory, Methods and Applications, vol. 75, no. 4, pp. 2154-2165, 2012. 
[19] A. Felhi, S. Sahmim, and H. Aydi, "Ulam-hyers stability and well-posedness of fixed point problems for $\alpha-\lambda$-metric spaces," Fixed Point Theory and Applications, vol. 2016, no. 1, 20 pages, 2016.

[20] V. L. Rosa and P. Vetro, "Common fixed points for $\alpha-\psi-\phi$ contractions in generalized metric spaces," Nonlinear Analysis: Modelling and Control, vol. 19, no. 1, pp. 43-54, 2014. 


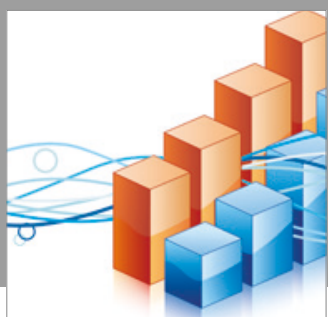

Advances in

Operations Research

vatersals

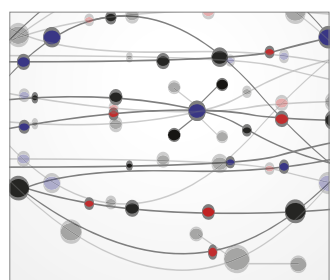

\section{The Scientific} World Journal
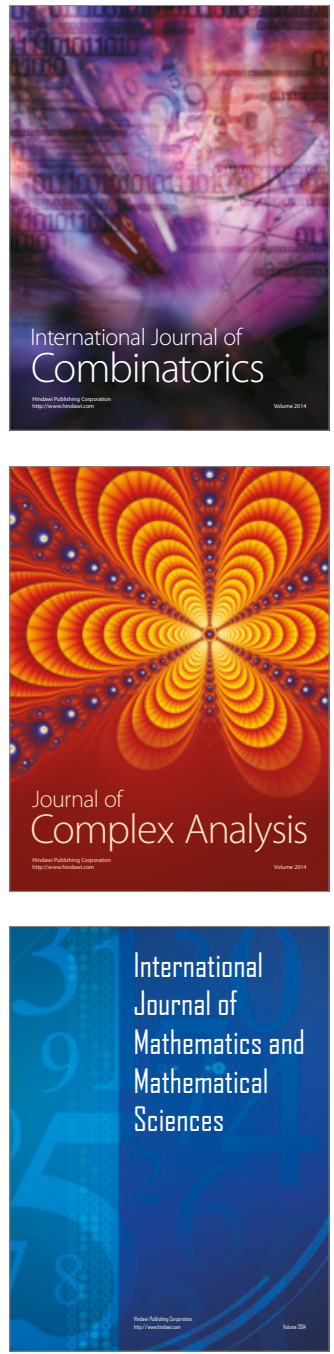
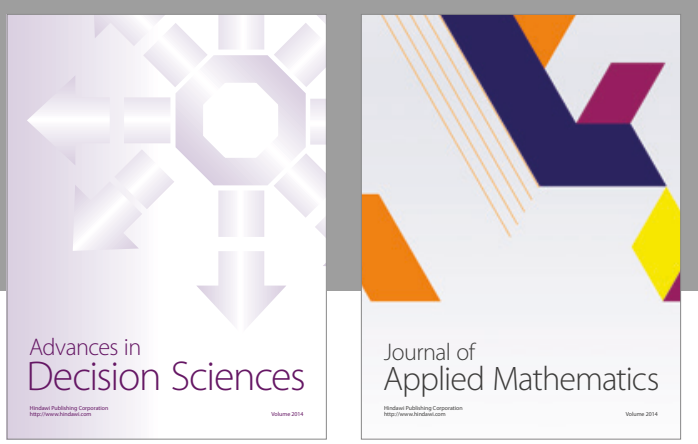

Algebra

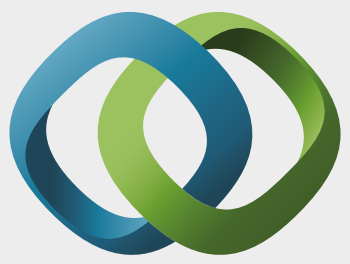

\section{Hindawi}

Submit your manuscripts at

https://www.hindawi.com
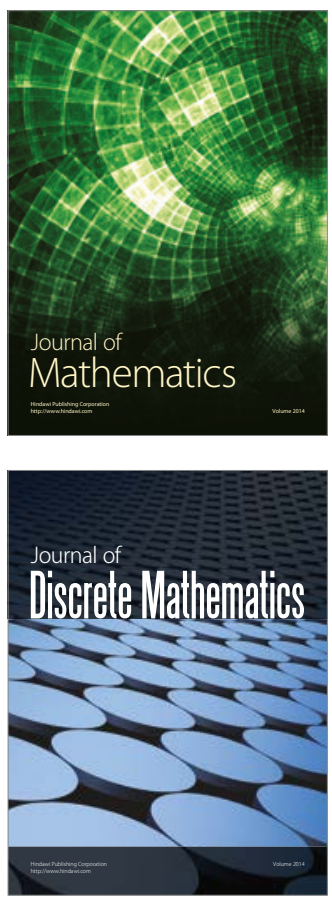

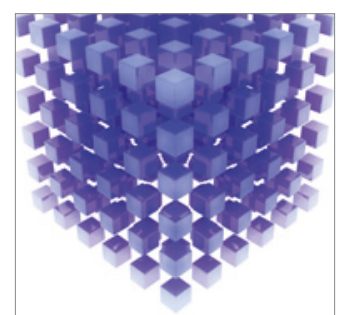

Mathematical Problems in Engineering
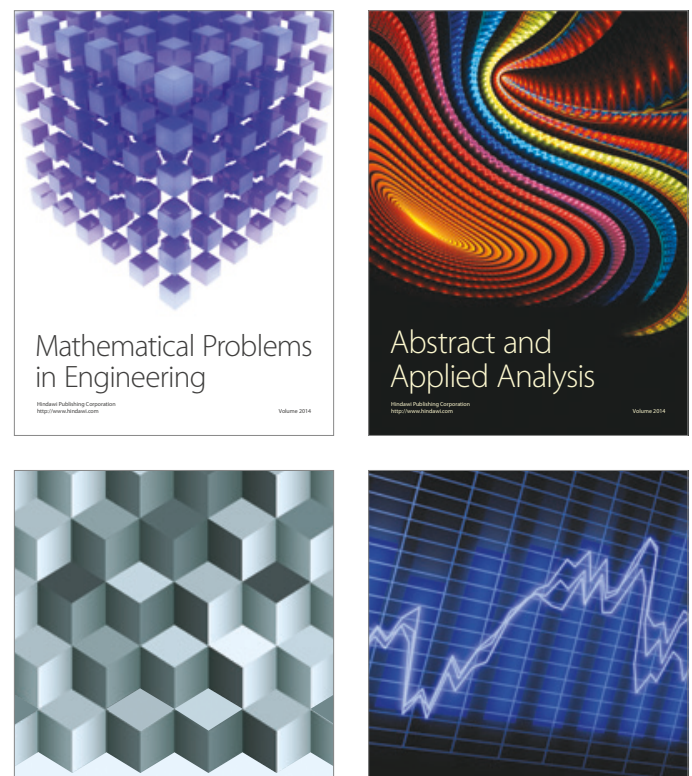

Journal of

Function Spaces

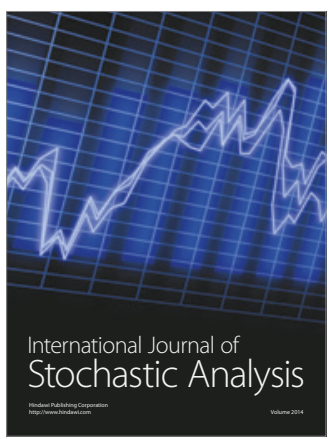

Probability and Statistics
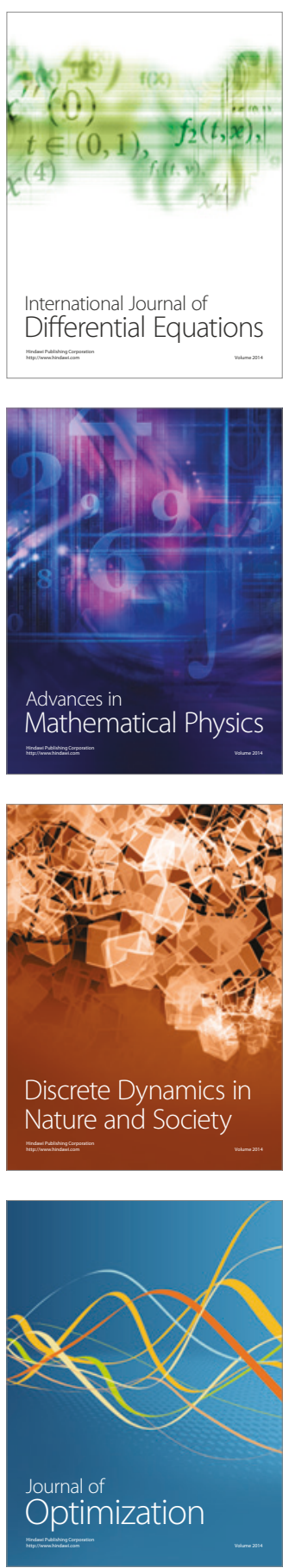